\title{
Article
}

\section{Influence of the Interface Composition to the Superconductivity of Ti/PdAu Films}

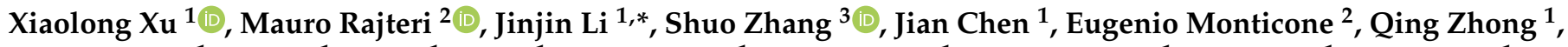 \\ Huifang Gao ${ }^{1}$, Wei $\mathrm{Li}^{1}{ }^{1} \mathrm{Xu} \mathrm{Li}^{1}$, Qi Li ${ }^{1}$, Yuan Zhong ${ }^{1}$, Wenhui Cao ${ }^{1}$, Shijian Wang ${ }^{1}$, Ying Gao ${ }^{1}$, Zheng Liu ${ }^{1}$ \\ and Xueshen Wang $1, *(\mathbb{D}$
}

1 National Institute of Metrology (NIM), Beijing 100029, China; xiaolong.xu@nim.ac.cn (X.X.); chenjian@nim.ac.cn (J.C.); zhongq@nim.ac.cn (Q.Z.); gaohf@nim.ac.cn (H.G.); liwei@nim.ac.cn (W.L.); li-xu@nim.ac.cn (X.L.); liqi@nim.ac.cn (Q.L.); zhongyuan@nim.ac.cn (Y.Z.); caowh@nim.ac.cn (W.C.); wangshj@nim.ac.cn (S.W.); gaoying2018@nim.ac.cn (Y.G.); lzheng@nim.ac.cn (Z.L.)

2 Istituto Nazionale di Ricerca Metrologica (INRiM), 10135 Torino, Italy; m.rajteri@inrim.it (M.R.); e.monticone@inrim.it (E.M.)

3 Center for Transformative Science, ShanghaiTech University, Shanghai 201210, China; shuozhang@shanghaitech.edu.cn

* Correspondence: jinjinli@nim.ac.cn (J.L.); wangxs@nim.ac.cn (X.W.); Tel.: +86-10-6452-6134 (J.L.); +86-10-6452-4555 (X.W.)

check for updates

Citation: Xu, X.; Rajteri, M.; Li, J.;

Zhang, S.; Chen, J.; Monticone, E.;

Zhong, Q.; Gao, H.; Li, W.; Li, X.; et al. Influence of the Interface

Composition to the

Superconductivity of Ti/PdAu Films.

Nanomaterials 2021, 11, 39. https://

dx.doi.org/10.3390/nano11010039

Received: 29 November 2020

Accepted: 22 December 2020

Published: 25 December 2020

Publisher's Note: MDPI stays neutral with regard to jurisdictional claims in published maps and institutional affiliations.

Copyright: () 2020 by the authors. Licensee MDPI, Basel, Switzerland. This article is an open access article distributed under the terms and conditions of the Creative Commons Attribution (CC BY) license (https: / creativecommons.org/ licenses/by/4.0/).

\begin{abstract}
In this work, the interface composition of the superconducting Ti/PdAu bilayer is tuned by an annealing process in $\mathrm{N}_{2}$ from 100 to $500{ }^{\circ} \mathrm{C}$ to control the superconducting transition temperature $\left(T_{\mathrm{c}}\right)$. This Ti-PdAu composition layer is characterized with a high-resolution transmission electron microscopy (HRTEM) and energy-dispersive spectrometer (EDS) to show the infiltration process. The surface topography, electrical, and cryogenic properties are also shown. The inter-infiltration of $\mathrm{Ti}$ and PdAu induced by the thermal treatments generates an intermixed layer at the interface of the bilayer film. Due to the enforced proximity effect by the annealing process, the $T_{\mathrm{c}}$ of $\mathrm{Ti}(55 \mathrm{~nm}) / \mathrm{PdAu}$ $(60 \mathrm{~nm})$ bilayer thin films is tuned from an initial value of 243 to $111 \mathrm{mK}$ which is a temperature that is suitable for the application as the function unit of a superconducting transition edge sensor.
\end{abstract}

Keywords: Ti/PdAu; proximity effect; interfere; composition; annealing; superconductivity

\section{Introduction}

Superconducting transition-edge sensors (TES) [1] have been widely used in the infrared-visible region [2], and for X-ray [3] and $\gamma$-ray [4] detection with the superiority of photon-number and energy resolving capability, high quantum efficiency, and negligible dark-count rate. TES usually works on the sharp transition edge between the superconducting and normal state of superconducting films, and the energy resolution $(\Delta E)$ in the strong electro-thermal feedback is expressed as follows [5]:

$$
\Delta E=\sqrt{\frac{4 k T_{c}^{2} C \sqrt{n / 2}}{\alpha}} \propto T_{\mathcal{C}}^{\frac{3}{2}}
$$

where $k$ is the Boltzmann constant, $n$ is an exponent factor of thermal conductance, $C$ and $\alpha$ are the heat capacity and thermal sensitivity of a superconducting thin film which acts the key function unit of a TES. From (1), we can see that the $T_{\mathrm{c}}$ should be as low as possible to obtain a better $\Delta E[6]$.

Superconducting Ti films have been widely used especially for optical TES. The $T_{\mathrm{C}}$ of pure Ti is from 360 to $500 \mathrm{mK}$ [7-11] as the thicknesses changes. However, for a better $\Delta E$, the $T_{\mathrm{c}}$ should be $\approx 100 \mathrm{mK}$ [12-17]. The tunable range of $T_{\mathrm{c}}$ of a pure Ti film is limited. The common method to control the $T_{\mathrm{c}}$ is exploiting the proximity effect [18-21] between a superconducting and a normal metal film. According to the Usadel theory $[19,22]$, the $T_{\mathrm{c}}$ 
of a bilayer film composed by a superconducting film layer and a normal metal film layer is expressed as:

$$
\begin{gathered}
T_{c}=T_{c 0}\left[\frac{d_{s}}{d_{0}} \frac{1}{1.13\left(1+\frac{1}{\beta}\right)} \frac{1}{t}\right]^{\beta} \\
\frac{1}{d_{0}}=\frac{\pi}{2} k T_{c 0} \lambda_{F}^{2} n_{s} \\
\beta=d_{n} n_{n} / d_{s} n_{s}
\end{gathered}
$$

Here $d_{\mathrm{n}}$ and $d_{\mathrm{s}}$ are the thickness of the normal metal film and the superconducting metal film, $n_{\mathrm{n}}$ and $n_{\mathrm{s}}$ are the density of states for the respective materials, $T_{\mathrm{c} 0}$ is the $T_{\mathrm{c}}$ of the superconducting metal film, $\lambda_{\mathrm{F}}$ is the Fermi wavelength of the normal metal, and $t$ is the unitless modified parameter to describe the transmission through the interface of the bilayer film. From (2), we can see that there are two methods to tune the $T_{\mathrm{c}}$ of a pure Ti film: one is changing the thickness ratio $d_{\mathrm{n}} / d_{\mathrm{s}}$, the other is tuning the interface property $t$. The interface status plays a key role to influence the $T_{\mathrm{c}}$. Au is usually used as the normal metal for Ti [23-32]. However, nanometer Au films are not stable, and the surface roughness becomes larger as time goes by. Moreover, the baking temperature obviously affected the $\mathrm{T}_{\mathrm{C}}$ of $\mathrm{Ti} / \mathrm{Au}$ films even below $100{ }^{\circ} \mathrm{C}$ [27].

In this paper, a PdAu alloy film, which is more stable than a pure Au film, is used as the normal metal film to tune the $T_{\mathrm{c}}$ of Ti films. An annealing process in $\mathrm{N}_{2}$ from 100 to $500{ }^{\circ} \mathrm{C}$ is performed. The inter-infiltration of $\mathrm{Ti}$ and $\mathrm{PdAu}$ induced by the thermal treatments enforces the proximity effect and tunes the $T_{c}$ from an initial value of 243 to $111 \mathrm{mK}$. From the results of the high-resolution transmission electron microscopy (HRTEM), energy-dispersive spectrometer (EDS), X-ray diffraction (XRD), surface topography, and electrical characterization, to obviously tune the $T_{\mathrm{c}}(>10 \%)$, the annealing temperature should be above $100{ }^{\circ} \mathrm{C}$, which is beneficial for the nanofabrication process and application of TES using Ti/PdAu films.

\section{Materials and Methods}

A commercial 3-inch monocrystalline silicon substrate with a $500 \mathrm{~nm}$ low-pressure chemical vapor deposition (LPCVD) $\mathrm{SiN}_{\mathrm{x}}$ layer is cleaned with acetone, isopropyl alcohol, ethanol, de-ionized water, and then dried with $\mathrm{N}_{2}$, in sequence. A Ti $(55 \mathrm{~nm}) / \mathrm{PdAu}(60 \mathrm{~nm})$ bilayer thin film is deposited on it using an ultrahigh vacuum confocal DC magnetron sputtering system (Sky technology development ltd., Shenyang, China). The base pressure of the main chamber is $\approx 10^{-6} \mathrm{~Pa}$. The deposition rates are $1.1 \AA$ /s for the Ti and $7.4 \AA / \mathrm{s}$ for the PdAu layer. During the deposition process, the substrate temperature is kept at $20^{\circ} \mathrm{C}$ by a circulating water cooler. The films are cut into slices of $5 \mathrm{~mm} \times 10 \mathrm{~mm}$ for the following annealing process.

The annealing process is performed in high-purity $\mathrm{N}_{2}$ as the protection atmosphere with a programmable UniTemp GmbH RTP-100 oven (Universal Temperature Processes, Pfaffenhofen, Germany). Six slices of $5 \mathrm{~mm} \times 10 \mathrm{~mm}$ samples from the same 3-inch film is used to perform the annealing process with the temperature ranges from 100 to $500{ }^{\circ} \mathrm{C}$ respectively, as shown in Figure 1. The films are firstly heated to $120^{\circ} \mathrm{C}$ with a rate of $1{ }^{\circ} \mathrm{C} / \mathrm{s}$ and kept for $2 \mathrm{~min}$ to remove the humidity. Above $120^{\circ} \mathrm{C}$, the heating rate is set to $0.5^{\circ} \mathrm{C} / \mathrm{s}$, and the temperature is kept at $225^{\circ} \mathrm{C}$ for $10 \mathrm{~min}$ to make the potential organic matter gasified out. The maximum temperatures are held for $2 \mathrm{~h}$ to realize sufficient annealing. Finally, the cooling rate is set as $-1{ }^{\circ} \mathrm{C} / \mathrm{s}$ to room temperature. 


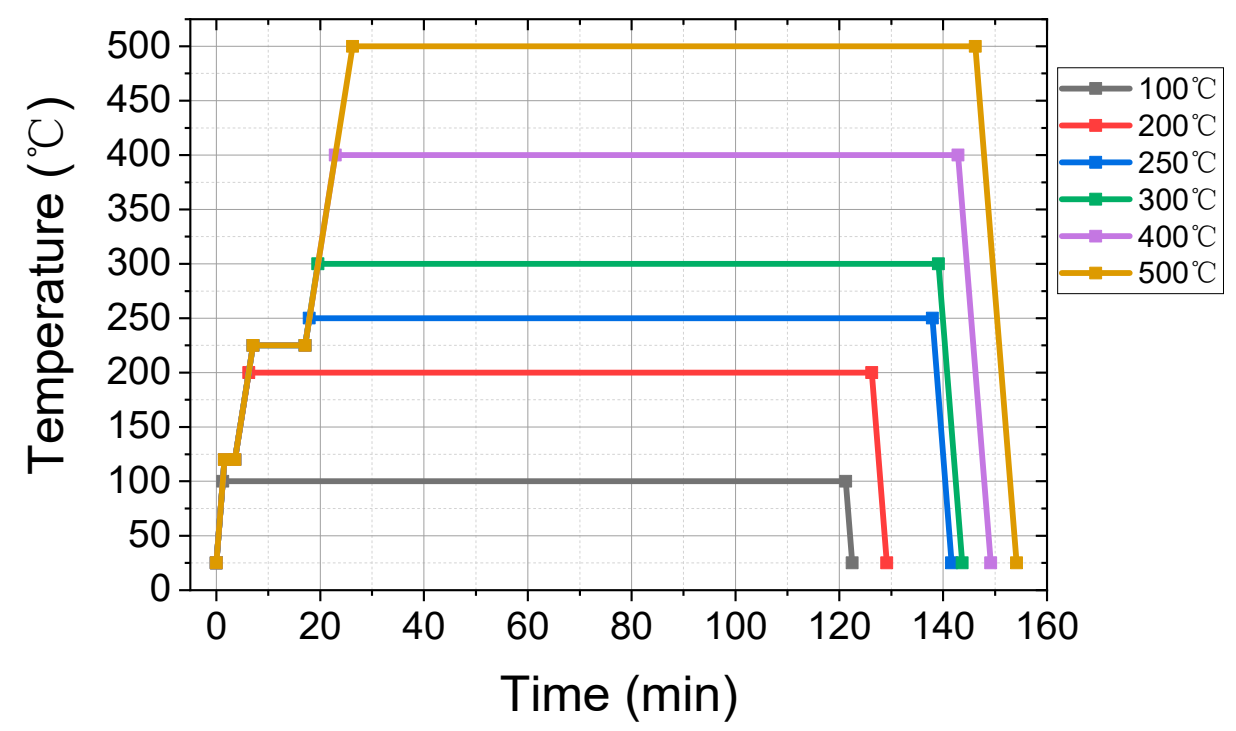

Figure 1. The annealing progress of $\mathrm{Ti}(55 \mathrm{~nm}) / \mathrm{PdAu}(60 \mathrm{~nm})$ films.

\section{Results}

\subsection{Morphology of Interface Composition}

After the annealing process, the cross-section of the bilayer Ti/PdAu films are fabricated by a focus ion beam milling method with a Pt layer as the protective layer. Then a $55 \mathrm{~nm}$ Ti layer and $60 \mathrm{~nm}$ PdAu layer are clearly shown in the SEM and EDS images of Figure 2. The interface is clear below $300{ }^{\circ} \mathrm{C}$, and the intermixed layer is not obviously shown in Figure 2a-d, presumably because the extent of inter-diffusion is not sufficient for a FEI Helios NanoLab G3 SEM characterization (FEI, Hillsboro, OR, USA). From the EDS analysis (FEI, Hillsboro, OR, USA), when the annealing temperature is lower than $300^{\circ} \mathrm{C}$, the atoms diffuse only several nanometers to $\approx 10 \mathrm{~nm}$ at the interface and slightly deeper and deeper when the annealing temperature increases.

However, when the annealing temperature is $400{ }^{\circ} \mathrm{C}$, the interface shows obviously an atomic inter-diffusion blurring the interface, as shown in Figure 2f. The two layers start to $\mathrm{mix}$, and a Ti-PdAu intermixed layer with a thickness around $40 \mathrm{~nm}$ generates. Moreover, when the annealing temperature rises to $500{ }^{\circ} \mathrm{C}$, as shown in Figure $2 \mathrm{~g}$, atomic diffusion is enhanced to the extent that Ti diffuses uniformly throughout the whole structure and $\mathrm{PdAu}$ diffuses to the bottom layer. The atomic diffusion at the interface will enforce the proximity effect and tune the $T_{\mathrm{C}}$ of the Ti/PdAu films [22].

Figure 3 shows the Ti, $\mathrm{Pd}$, and $\mathrm{Au}$ surface elements distribution at the cross-section of the $\mathrm{Ti} / \mathrm{PdAu}$ layer and demonstrates the diffusion process of $\mathrm{Ti}$ and $\mathrm{PdAu}$ at the interface. The element distribution of the bilayer structure is separated at the Z-axis to Ti, PdAu bilayers. In Figure $3 \mathrm{a}$, the $\mathrm{Pd}$ and Au elements stay at the same altitude, which means $\mathrm{PdAu}$ is the alloy that stays at same layer. The Ti layer is just below the PdAu layer. When the annealing temperature increases, the $\mathrm{Ti}, \mathrm{Pd}$, and $\mathrm{Au}$ atoms cross the interface and start the diffusion process. When the annealing temperature rises to $400{ }^{\circ} \mathrm{C}$, as shown in Figure $2 \mathrm{f}$, there is a $40 \mathrm{~nm}$ thick layer in which $\mathrm{Ti}, \mathrm{Pd}$ and $\mathrm{Au}$ atoms are intermixed. When the annealing temperature increases to $500{ }^{\circ} \mathrm{C}$, as shown in Figure $2 \mathrm{~g}$, Ti atoms are distributed throughout the original area of the $\mathrm{Ti} / \mathrm{PdAu}$ layers and $\mathrm{Pd}$ as well as $\mathrm{Au}$ atoms diffuse into the lower layer. The whole bilayer area is converted into a Ti-Pd-Au intermixed layer. 

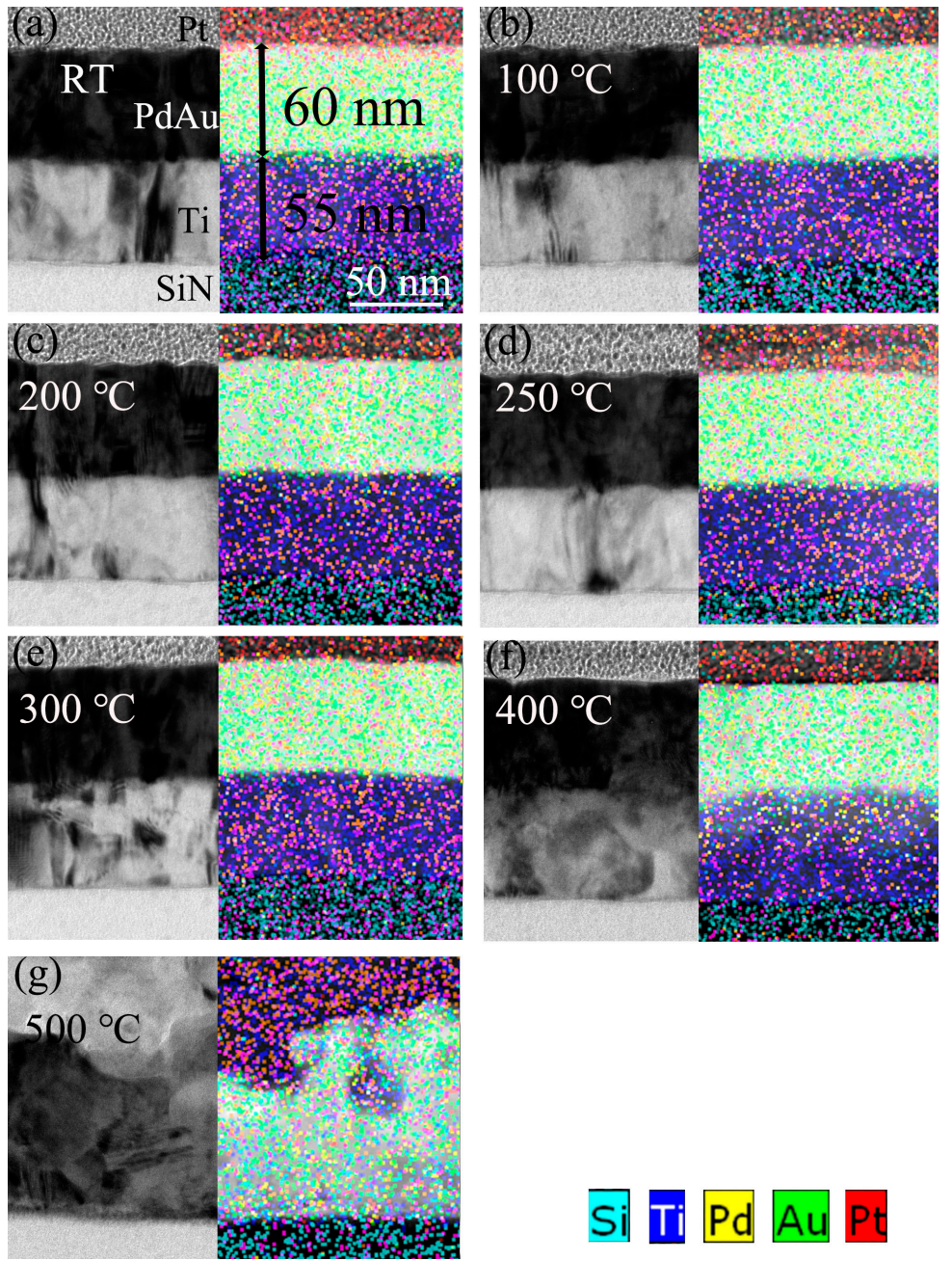

Figure 2. SEM and EDS of the cross-section of the Ti/PdAu bilayer films, annealing temperature at (a) RT, (b) $100{ }^{\circ} \mathrm{C}$, (c) $200^{\circ} \mathrm{C}$, (d) $250{ }^{\circ} \mathrm{C}$, (e) $300{ }^{\circ} \mathrm{C}$, (f) $400{ }^{\circ} \mathrm{C}$, (g) $500{ }^{\circ} \mathrm{C}$.
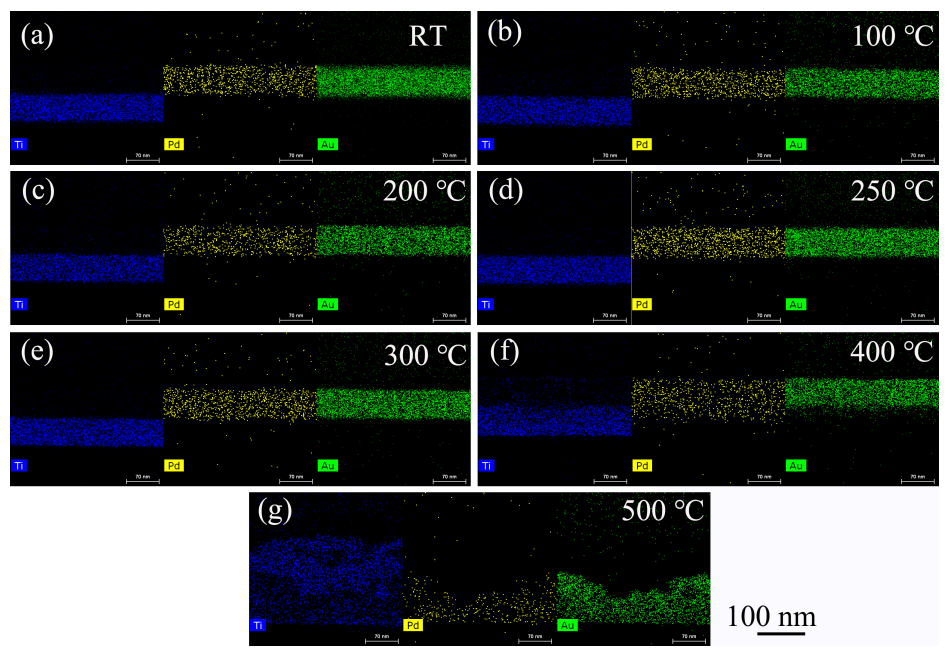

$10 \underline{0 \mathrm{~nm}}$

Figure 3. Element surface distribution of the cross-section of $\mathrm{Ti} / \mathrm{PdAu}$ bilayer films, annealing temperature at (a) RT, (b) $100{ }^{\circ} \mathrm{C},(\mathbf{c}) 200^{\circ} \mathrm{C}$, (d) $250{ }^{\circ} \mathrm{C}$, (e) $300{ }^{\circ} \mathrm{C},(\mathbf{f}) 400{ }^{\circ} \mathrm{C},(\mathrm{g}) 500{ }^{\circ} \mathrm{C}$.

The Ti/PdAu interface is also characterized by FEI Tecnai F20 HRTEM (FEI, Hillsboro, OR, USA), as shown in Figure 4. The spacing (bright part) between the (110) lattice planes 
of the cubic Ti crystal is $2.34 \AA$, and that of the (111) planes of cubic Au and Pd (dark part) are $2.35 \AA$ and $2.25 \AA$ separately. Considering that the lattice planes of $\mathrm{Ti}$ (110) and $\mathrm{Au}(111)$ are quite similar, $\mathrm{Pd}$ (111) is selected as the characteristic factor to identify atomic diffusion across the interface. $\mathrm{Pd}$ (111) lattice planes can be identified only near the interface when the annealing temperature is low. When the annealing temperature rises above $300{ }^{\circ} \mathrm{C}$, the $\mathrm{Pd}$ atom crosses the interface and diffuse into the Ti layer. For $500{ }^{\circ} \mathrm{C}$, the Ti and $\mathrm{PdAu}$ phase mix, redistribute, and enrich in inversion. The HRTEM results shows the consistency with the EDS characterization.
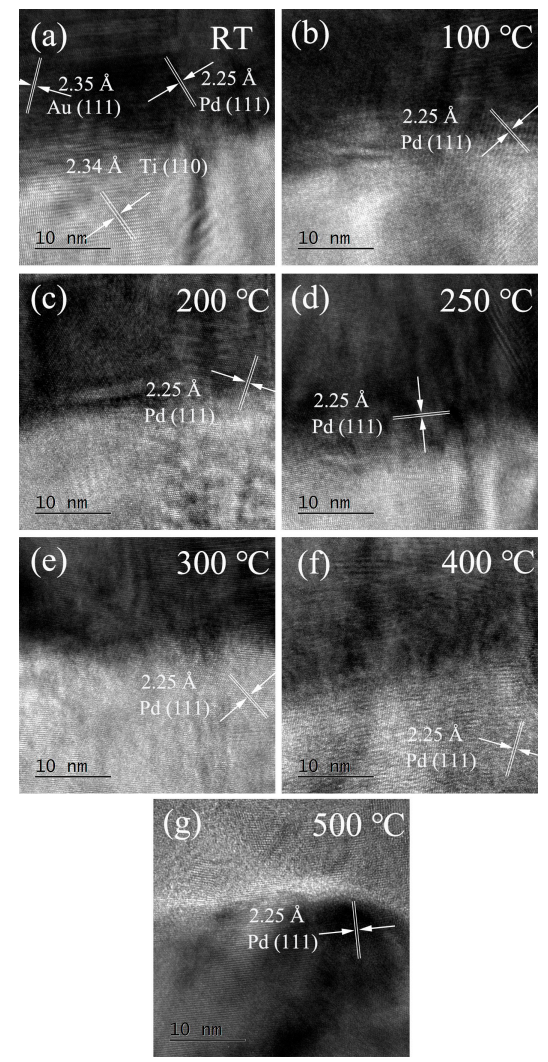

Figure 4. HRTEM characterization of Ti/PdAu interface of the Ti/PdAu bilayer thin film, annealing temperature at (a) RT, (b) $100{ }^{\circ} \mathrm{C}$, (c) $200{ }^{\circ} \mathrm{C}$, (d) $250{ }^{\circ} \mathrm{C}$, (e) $300{ }^{\circ} \mathrm{C}$, (f) $400{ }^{\circ} \mathrm{C}$, (g) $500{ }^{\circ} \mathrm{C}$.

The roughness of the annealed $\mathrm{Ti} / \mathrm{PdAu}$ thin films is measured on a scan size of $2 \mu \mathrm{m} \times 2 \mu \mathrm{m}$ using a Veeco Dimension Icon system (Veeco, New York, NY, USA). The result of roughness $R_{\mathrm{q}}$ (root mean surface squared roughness) is plotted vs. annealing temperature as shown in Figure 5. When the annealing temperature is below $300{ }^{\circ} \mathrm{C}$, the $R_{\mathrm{q}}$ is around $0.6 \mathrm{~nm}$, which is similar or better than in previous work $[7,12,15,20,30]$, as shown in Table 1. With good morphological property (lower roughness), the thin films present better performance in proximity effect and robust process compatibility in further TES fabrication with the multilayer readout wiring.

$R_{\mathrm{q}}$ increases to $1.4 \mathrm{~nm}$ at $400^{\circ} \mathrm{C}$. Afterwards, an abrupt jump to $6.4 \mathrm{~nm}$ (i.e., 1 order of magnitude) is observed as the annealing temperature reaches $500^{\circ} \mathrm{C}$. It is mainly attributed to the atom diffusion, which also could be obvious in Figure $3 \mathrm{~g}$. 


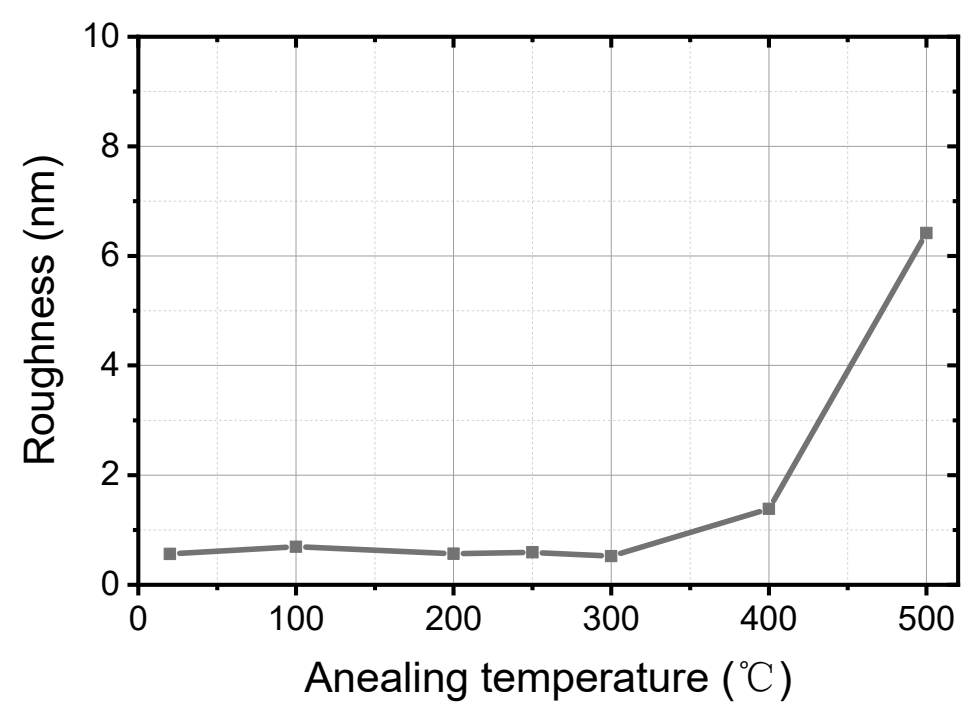

Figure 5. Roughness of $\mathrm{Ti} / \mathrm{PdAu}$ bilayer thin film vs. annealing temperature.

Table 1. Roughness of the superconductive thin film used in TES.

\begin{tabular}{ccccccc}
\hline & Ref. [7] & Ref. [15] & Ref. [12] & Ref. [20] & Ref. [30] & This Work \\
\hline $\begin{array}{c}\text { Superconductive } \\
\text { materials }\end{array}$ & $\mathrm{Ti}$ & $\mathrm{Mo}$ & $\mathrm{Mo} / \mathrm{Cu}$ & $\mathrm{Ti} / \mathrm{Au}$ & $\mathrm{Ti} / \mathrm{Au}$ & $\mathrm{Ti} / \mathrm{PdAu}$ \\
Thickness & $100 \mathrm{~nm}$ & $200 \mathrm{~nm}$ & $72 \mathrm{~nm} /$ & $40 \mathrm{~nm} /$ & $100 \mathrm{~nm} /$ & $55 \mathrm{~nm} /$ \\
Roughness $R_{\mathrm{q}}$ & $1.5 \mathrm{~nm}$ & $1.7 \mathrm{~nm}$ & $0.75 \mathrm{~nm}$ & $4.5 \mathrm{~nm}$ & $0.4 \mathrm{~nm}$ & $0.6 \mathrm{~nm}$ \\
\hline
\end{tabular}

\subsection{Structure and Phase}

The X-ray diffraction (XRD) pattern of the films was performed using a Panalytical $X^{\prime}$ Pert PRO MPD diffractometer $(\mathrm{Cu} \lambda \mathrm{K} \alpha=1.541874 \AA$ ) (Malvern Panalytical Ltd, Malvern, United Kingdom) with the incidence angle fixed at $0.5^{\circ}$, and the $2 \theta$ angle ranged from $10^{\circ}$ to $90^{\circ}$ with a step of $0.05^{\circ}$, as shown in Figure 6. Two strong preferential orientation of PdAu alloy (Gold, JCPDS card \# 04-0784 and Palladium, JCPDS card \# 46-1043) peaks are clearly recorded at $2 \theta=39.52^{\circ}$ and $66.82^{\circ}$, which represent the (111) and (220) planes of the $\mathrm{PdAu}$ alloy phase. In addition, two weaker diffraction signals at $2 \theta=45.73^{\circ}$ and $80.26^{\circ}$ correspond to the PdAu alloy (200) and (311) planes, respectively [33-36]. The peak at $2 \theta=69.48^{\circ}$ is mainly due to Ti (211) planes (Titanium, JCPDS card \# 44-1288), and another $\mathrm{Ti}$ (110) plane appears at $2 \theta=38.48^{\circ}$, which is merged under the high intensity of the $\mathrm{PdAu}$ (111) plane. PdAu alloy has heavy density, which could easily scatter the X-ray from the copper cathode, and the small incidence angle $\left(0.5^{\circ}\right)$ increases the path length of the $\mathrm{X}$-ray. These effects make the signal from the Ti layer weak. When the annealing temperature is $500{ }^{\circ} \mathrm{C}$, two strong peaks of the rutile $\mathrm{TiO}_{2}$ (110) phase $\left(\mathrm{TiO}_{2}\right.$, JCPDS card \#21-1276) appear at $2 \theta=27.45^{\circ}$, and the rutile $\mathrm{TiO}_{2}$ (211) phase appears at $2 \theta=54.32^{\circ}$. Thermal oxidation of the $\mathrm{Ti}$ at $500{ }^{\circ} \mathrm{C}$ causes the appearance of the $\mathrm{TiO}_{2}$ peaks. 


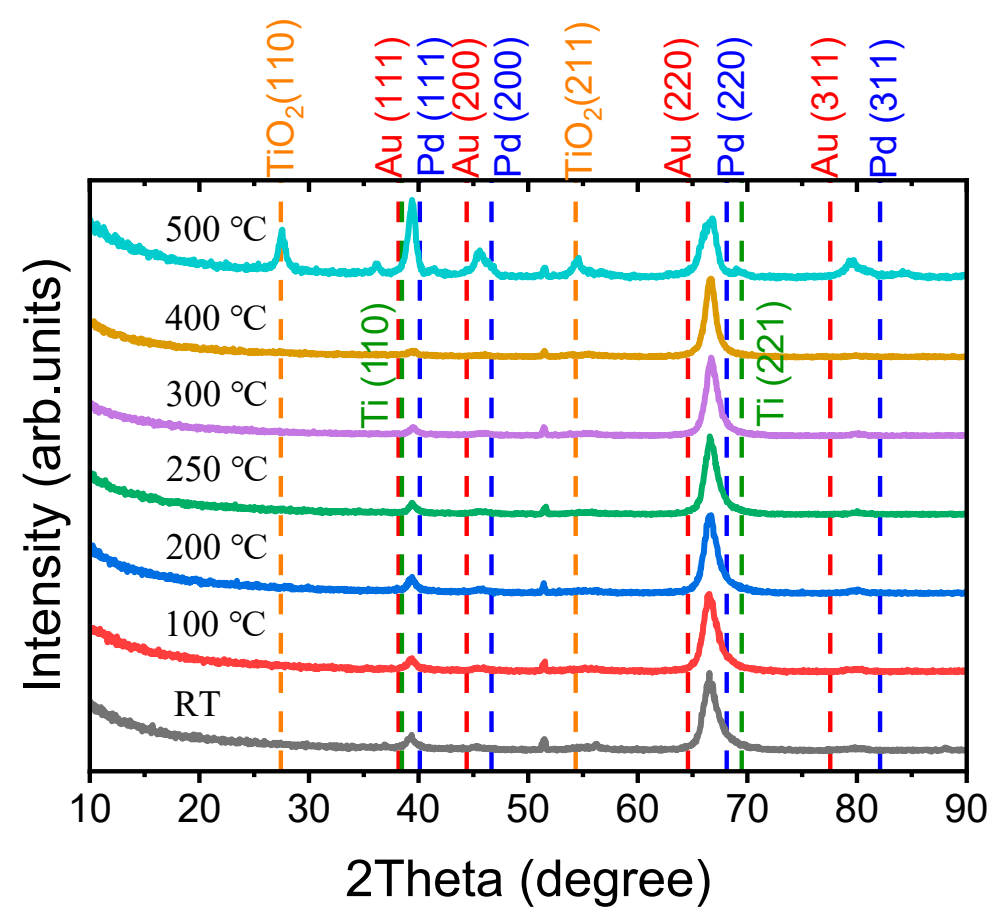

Figure 6. XRD pattern of annealed Ti/PdAu bilayer thin films.

\subsection{Electrical Property}

The sheet resistance $R_{\square}$ of Ti/PdAu bilayer films is an important factor influenced by the annealing temperature and affects the sensitivity of the voltage biased TES. $R_{\square}$ is determined by mapping measurements with a CDE Resmap 178 system (Creative Design Engineering Inc., Cupertino, CA, USA) based on the van der Pauw method. Figure 7 shows the $R_{\square}$ vs. temperatures. When the annealing temperature is lower than $300{ }^{\circ} \mathrm{C}$, the $R_{\square}$ is around $3.5 \Omega / \square$. Above $300{ }^{\circ} \mathrm{C}, R_{\square}$ significantly increases because of the thermal oxidation of $\mathrm{Ti}$ and interface composition.

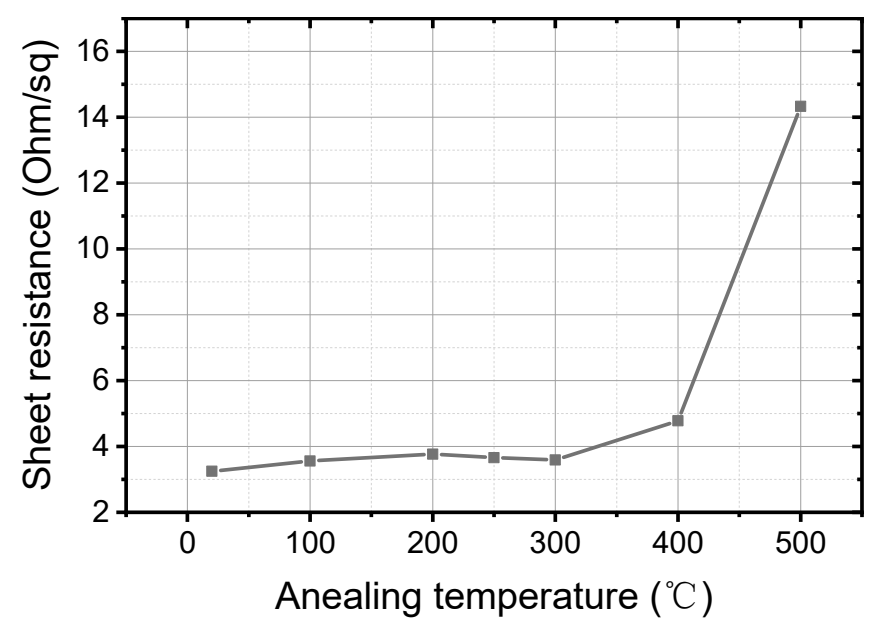

Figure 7. Sheet resistance vs. annealing temperature of Ti/PdAu bilayer thin film.

\subsection{Cryogenic Property}

Figure 8 shows the resistance temperature curve of the annealed $\mathrm{Ti} / \mathrm{PdAu}$ films measured in an adiabatic demagnetization refrigerator (ADR) system (High Precision Devices, Inc., Boulder, CO, USA). After the annealing at $100{ }^{\circ} \mathrm{C}$, the $T_{\mathrm{C}}$ is $236.5 \mathrm{mK}$, which is slightly lower than the unannealed films $(243.5 \mathrm{mK})$. As the annealing temperature increases, the $T_{\mathrm{c}}$ gradually decreases from $160.4 \mathrm{mK}\left(200{ }^{\circ} \mathrm{C}\right)$ to $147.4 \mathrm{mK}\left(250{ }^{\circ} \mathrm{C}\right)$, and 
then to $111.5 \mathrm{mK}\left(300{ }^{\circ} \mathrm{C}\right)$. Above $400{ }^{\circ} \mathrm{C}$, the temperature maybe too high as shown in the HRTEM and SEM characterization, the Ti/PdAu films do not show superconducting transition down to $30 \mathrm{mK}$. For the TES application equipped in a dilution refrigerator or $\mathrm{ADR}, T_{\mathrm{C}} \approx 100 \mathrm{mK}$ is suitable. Therefore, the annealing process at $300{ }^{\circ} \mathrm{C}$ is applicable.

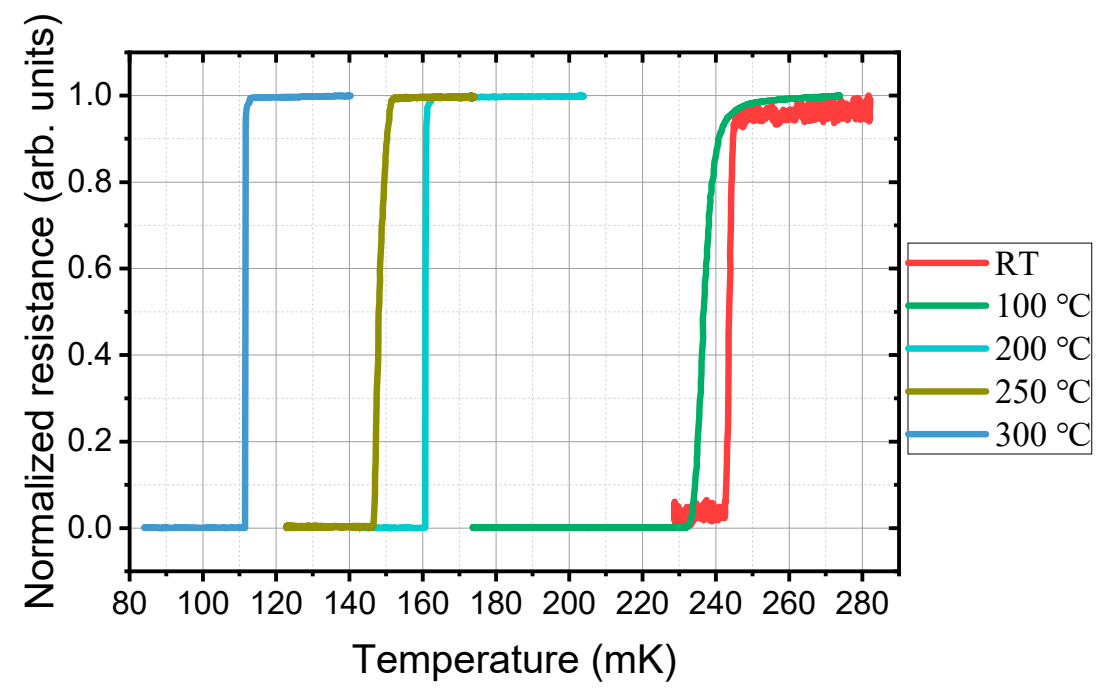

Figure 8. The effect of annealed treatment on the $T_{\mathrm{c}}$ of $\mathrm{Ti} / \mathrm{PdAu}$ bilayer films.

\section{Conclusions}

A $60 \mathrm{~nm}$ PdAu film is deposited on the top surface of $55 \mathrm{~nm}$ Ti to tune the $T_{\mathrm{c}}$ of the Ti film. An annealing process is performed to modify the proximity effect. After annealing, Ti and $\mathrm{PdAu}$ atoms recombine at the Ti/PdAu interface to form an intermixed layer. Due to the intermixed layer, the $T_{\mathrm{C}}$ of the Ti/PdAu bilayer film is successfully tuned from $243 \mathrm{mK}$ to the ideal $111 \mathrm{mK}$, which is optimal for TES applications. The $T_{\mathrm{c}}$ could be controlled by the interface property without changing the thickness ratio between the superconducting and normal metal. The annealing temperature should be below $400{ }^{\circ} \mathrm{C}$. Otherwise, the bilayer film will show a normal metal state even at the temperature down to $50 \mathrm{mK}$. The Ti-PdAu intermixed layer at the interface is characterized by SEM, EDS and HRTEM to analyze the mechanism of $T_{\mathrm{c}}$ adjustment. As a new superconducting/normal film combination, annealed $\mathrm{Ti} / \mathrm{PdAu}$ bilayer films have shown great potential for TES applications.

Author Contributions: X.X., and E.M., conceived and designed the experiments; J.C., Q.Z., Y.Z., W.C. and S.W. performed the experiments; M.R., S.Z. made the cryogenic measurement; H.G., W.L. X.L., Q.L., Y.G. and Z.L. performed the analyzed the data; J.L. and X.W. provided the concept of this research and managed all the experimental and writing process as the corresponding authors; all authors discussed the results and commented on the manuscript. All authors have read and agreed to the published version of the manuscript.

Funding: This research was funded by Young Scientists Fund of the National Natural Science Foundation of China (Grant No. 61901432, 61701470), Science and technology project of State Administration for Market Regulation, China (2020MK153, 2019MK112) and the Fundamental Research Projects in Basic Scientific Research at NIM (AKYZD1903).

Conflicts of Interest: The authors announce no conflict of interest. 


\section{References}

1. Lita, A.E.; Miller, A.J.; Nam, S.W. Counting near-infrared single-photons with 95\% efficiency. Opt. Express 2008, 16, 3032. [CrossRef] [PubMed]

2. Taralli, E.; Lolli, L.; Portesi, C.; Monticone, E.; Rajteri, M.; Wang, T.-S.; Chen, J.-K.; Zhou, X. Reduced Active Area in TransitionEdge Sensors for Visible-NIR Photon Detection: A Comparison of Experimental Data and Two-Fluid Model. IEEE Trans. Appl. Supercond. 2015, 25, 1-4. [CrossRef]

3. Jaeckel, F.T.; Ambarish, C.V.; Christensen, N.; Gruenke, R.; Hu, L.; McCammon, D.; McPheron, M.; Meyer, M.; Nelms, K.L.; Roy, A.; et al. Energy Calibration of High-Resolution X-Ray TES Microcalorimeters with 3 eV Optical Photons. IEEE Trans. Appl. Supercond. 2019, 29, 3-6. [CrossRef] [PubMed]

4. Jaeckel, F.T.; Le, L.N.; Martin, K.W.; Boyd, S.T.P. Development of a Precision Scanning Optical Pulser for Low-Temperature Particle Detectors. IEEE Trans. Appl. Supercond. 2013, 23, 1301005. [CrossRef]

5. $\quad$ Enss, C. Cryogenic Particle Detection; Enss, C., Ed.; Springer: Berlin/Heidelberg, Germany, 2005; Volume 94, ISBN 978-3-540-31478-3.

6. Lolli, L.; Taralli, E.; Rajteri, M.; Numata, T.; Fukuda, D. Characterization of Optical Fast Transition-Edge Sensors With Optimized Fiber Coupling. IEEE Trans. Appl. Supercond. 2013, 23, 2100904. [CrossRef]

7. Xu, X.; Li, J.; Wang, X.; Zhong, Q.; Zhong, Y.; Cao, W.; Li, W.; Chen, J.; Zhao, Z.; Gao, Y.; et al. Investigation of Superconducting Titanium films for Transition Edge Sensors. In Proceedings of the 2020 Conference on Precision Electromagnetic Measurements (CPEM), Denver, CO, USA, 24-28 August 2020; pp. 1-2.

8. Bonetti, J.A.; Day, P.K.; Kenyon, M.; Kuo, C.L.; Turner, A.; LeDuc, H.G.; Bock, J.J. Characterization of antenna-coupled tes bolometers for the spider experiment. IEEE Trans. Appl. Supercond. 2009, 19, 520-523. [CrossRef]

9. Portesi, C.; Taralli, E.; Lolli, L.; Rajteri, M.; Monticone, E. Fabrication and Characterization of Fast TESs With Small Area for Single Photon Counting. IEEE Trans. Appl. Supercond. 2015, 25, 1-4. [CrossRef]

10. Vaccaro, D.; Siri, B.; Baldini, A.M.; Biasotti, M.; Cei, F.; Ceriale, V.; De Gerone, M.; Galli, L.; Gallucci, G.; Gatti, F.; et al. Tuning the TC of Titanium Thin Films for Transition-Edge Sensors by Annealing in Argon. J. Low Temp. Phys. 2018, 193, 1122-1128. [CrossRef]

11. Fukuda, D.; Fujii, G.; Numata, T.; Amemiya, K.; Yoshizawa, A.; Tsuchida, H.; Fujino, H.; Ishii, H.; Itatani, T.; Inoue, S.; et al. Titanium-based transition-edge photon number resolving detector with $98 \%$ detection efficiency with index-matched small-gap fiber coupling. Opt. Express 2011, 19, 870. [CrossRef]

12. Jaeckel, F.T.; Kripps, K.L.; Morgan, K.M.; Zhang, S.; McCammon, D. Fabrication of Superconducting Mo/Cu Bilayers Using Ion-Beam-Assisted e-Beam Evaporation. J. Low Temp. Phys. 2016, 184, 647-653. [CrossRef]

13. Jaeckel, F.T.; Kripps, K.L.; McCammon, D.; Wulf, D.; Zhang, S.; Zhou, Y. Effects of Uniaxial Stress on Mo and Mo/Cu Bilayer Superconducting Transitions. IEEE Trans. Appl. Supercond. 2017, 27, 1-4. [CrossRef] [PubMed]

14. Parra-Borderias, M.; Fernandez-Martinez, I.; Fabrega, L.; Camon, A.; Gil, O.; Costa-Kramer, J.L.; Gonzalez-Arrabal, R.; Sese, J.; Bueno, J.; Briones, F. Characterization of a Mo/Au thermometer for ATHENA. IEEE Trans. Appl. Supercond. 2013, $23,2300405$. [CrossRef]

15. Morgan, K.; Jaeckel, F.T.; Kripps, K.L.; McCammon, D. Ion-Beam-Assisted Deposition of Mo Thin Films for TES Applications. IEEE Trans. Appl. Supercond. 2015, 25, 1-5. [CrossRef]

16. Lolli, L.; Taralli, E.; Portesi, C.; Rajteri, M.; Monticone, E. Aluminum-Titanium Bilayer for Near-Infrared Transition Edge Sensors. Sensors 2016, 16, 953. [CrossRef]

17. Taralli, E.; Portesi, C.; Rocci, R.; Rajteri, M.; Monticone, E. Investigation of Ti/Pd bilayer for single photon detection. IEEE Trans. Appl. Supercond. 2009, 19, 493-495. [CrossRef]

18. Wakeham, N.A.; Adams, J.S.; Bandler, S.R.; Chervenak, J.A.; Datesman, A.M.; Eckart, M.E.; Finkbeiner, F.M.; Kelley, R.L.; Kilbourne, C.A.; Miniussi, A.R.; et al. Effects of Normal Metal Features on Superconducting Transition-Edge Sensors. J. Low Temp. Phys. 2018, 193, 231-240. [CrossRef]

19. Hilton, G.C.; Martinis, J.M.; Irwin, K.D.; Bergren, N.F.; Wollman, D.A.; Huber, M.E.; Deiker, S.; Nam, S.W. Microfabricated transition-edge X-ray detectors. IEEE Trans. Appl. Supercond. 2001, 11, 739-742. [CrossRef]

20. Kuromaru, G.; Kuwabara, K.; Miyazaki, N.; Suzuki, S.; Hosoya, S.; Koizumi, Y.; Ohashi, T.; Ishisaki, Y.; Ezoe, Y.; Yamada, S.; et al. Investigation of Surface Roughness Effect on Transition Edge Sensor Microcalorimeters Using Multilayer Readout Wiring. J. Low Temp. Phys. 2016, 184, 38-44. [CrossRef]

21. Sadleir, J.E.; Smith, S.J.; Robinson, I.K.; Finkbeiner, F.M.; Chervenak, J.A.; Bandler, S.R.; Eckart, M.E.; Kilbourne, C.A. Proximity effects and nonequilibrium superconductivity in transition-edge sensors. Phys. Rev. B Condens. Matter Mater. Phys. 2011, 84, 1-9. [CrossRef]

22. Martinis, J.M.; Hilton, G.C.; Irwin, K.D.; Wollman, D.A. Calculation of TC in a normal-superconductor bilayer using the microscopic-based Usadel theory. Nucl. Instruments Methods Phys. Res. Sect. A Accel. Spectrometers Detect. Assoc. Equip. 2000, 444, 23-27. [CrossRef]

23. Portesi, C.; Taralli, E.; Rocci, R.; Rajteri, M.; Monticone, E. Fabrication of Au/Ti TESs for optical photon counting. J. Low Temp Phys. 2008, 151, 261-265. [CrossRef]

24. Lolli, L.; Taralli, E.; Rajteri, M. Ti/Au TES to Discriminate Single Photons. J. Low Temp. Phys. 2012, 167, 803-808. [CrossRef]

25. Lolli, L.; Taralli, E.; Portesi, C.; Alberto, D.; Rajteri, M.; Monticone, E. Ti/Au transition-edge sensors coupled to single mode optical fibers aligned by Si V-groove. IEEE Trans. Appl. Supercond. 2011, 21, 215-218. [CrossRef] 
26. Taralli, E.; Gottardi, L.; Nagayoshi, K.; Ridder, M.; Visser, S.; Khosropanah, P.; Akamatsu, H.; van der Kuur, J.; Bruijn, M.; Gao, J.R. Characterization of High Aspect-Ratio TiAu TES X-ray Microcalorimeter Array Under AC Bias. J. Low Temp. Phys. 2020, 199, 80-87. [CrossRef]

27. Van Der Heijden, N.J.; Khosropanah, P.; Van Der Kuur, J.; Ridder, M.L. Diffusion behaviour in superconducting Ti/Au bilayers for SAFARI TES detectors. J. Low Temp. Phys. 2014, 176, 370-375. [CrossRef]

28. Taralli, E.; Pobes, C.; Khosropanah, P.; Fabrega, L.; Camón, A.; Gottardi, L.; Nagayoshi, K.; Ridder, M.L.; Bruijn, M.P.; Gao, J.R. AC/DC Characterization of a Ti/Au TES with Au/Bi Absorber for X-ray Detection. J. Low Temp. Phys. 2020, 199, 102-109. [CrossRef]

29. Nagayoshi, K.; Ridder, M.L.; Bruijn, M.P.; Gottardi, L.; Taralli, E.; Khosropanah, P.; Akamatsu, H.; Visser, S.; Gao, J.R. Development of a Ti/Au TES Microcalorimeter Array as a Backup Sensor for the Athena/X-IFU Instrument. J. Low Temp. Phys. 2020, 199, 943-948. [CrossRef]

30. Kengo, K.; Ezoe, Y.; Kitazawa, S.; Hayakawa, R.; Nunomura, K.; Ohashi, T.; Ishisaki, Y.; Yamada, S.; Hidaka, M.; Satoh, T.; et al. Study of Surface Roughness Effect on Super-Normal Transition of Ti/Au Transition Edge Sensor Calorimeters. J. Low Temp. Phys. 2018, 193, 349-355. [CrossRef]

31. Carter, F.W.; Ade, P.A.R.; Ahmed, Z.; Anderson, A.J.; Austermann, J.E.; Avva, J.S.; Thakur, R.B.; Bender, A.N.; Benson, B.A.; Carlstrom, J.E.; et al. Tuning SPT-3G Transition-Edge-Sensor Electrical Properties with a Four-Layer Ti-Au-Ti-Au Thin-Film Stack. J. Low Temp. Phys. 2018, 193, 695-702. [CrossRef]

32. Ridder, M.L.; Nagayoshi, K.; Bruijn, M.P.; Gottardi, L.; Taralli, E.; Khosropanah, P.; Akamatsu, H.; van der Kuur, J.; Ravensberg, K.; Visser, S.; et al. Study of TES Detector Transition Curve to Optimize the Pixel Design for Frequency-Division Multiplexing Readout. J. Low Temp. Phys. 2020, 199, 962-967. [CrossRef]

33. Xu, J.; Guo, S.; Jia, L.; Zhang, W. Palygorskite supported AuPd alloy nanoparticles as efficient nano-catalysts for the reduction of nitroarenes and dyes at room temperature. Nanomaterials 2018, 8, 1000. [CrossRef] [PubMed]

34. Schmidt, T.J.; Jusys, Z.; Gasteiger, H.A.; Behm, R.J.; Endruschat, U.; Boennemann, H. On the CO tolerance of novel colloidal $\mathrm{PdAu} /$ carbon electrocatalysts. J. Electroanal. Chem. 2001, 501, 132-140. [CrossRef]

35. Feng, Y.Y.; Liu, Z.H.; Xu, Y.; Wang, P.; Wang, W.H.; Kong, D.S. Highly active PdAu alloy catalysts for ethanol electro-oxidation. J. Power Sources 2013, 232, 99-105. [CrossRef]

36. Geraldes, A.N.; Da Silva, D.F.; Pino, E.S.; Da Silva, J.C.M.; De Souza, R.F.B.; Hammer, P.; Spinacé, E.V.; Neto, A.O.; Linardi, M.; Dos Santos, M.C. Ethanol electro-oxidation in an alkaline medium using $\mathrm{Pd} / \mathrm{C}, \mathrm{Au} / \mathrm{C}$ and $\mathrm{PdAu} / \mathrm{C}$ electrocatalysts prepared by electron beam irradiation. Electrochim. Acta 2013, 111, 455-465. [CrossRef] 